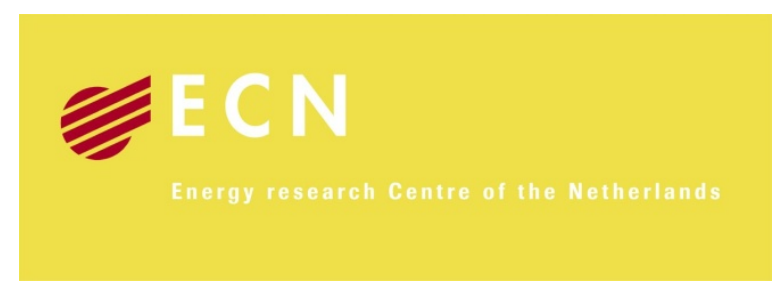

\title{
A Mobile Air Conditioning system operated by the engine waste heat
}

\author{
Daniela Magnetto (CRF) \\ Robert de Boer (ECN) \\ Abdelmajid Taklanti (Valeo)
}

This paper will be presented at the the SAE World congress, April 12-14 2011, Detroit, Michigan, USA 


\title{
A Mobile Air Conditioning system operated by the engine waste heat
}

\author{
Author, co-author list (Do NOT enter this information. It will be pulled from participant \\ tab in MyTechZone) \\ Affiliation (Do NOT enter this information. It will be pulled from participant tab in MyTechZone)
}

\author{
Copyright (C) 2011 SAE International
}

\begin{abstract}
This paper describes the development of a Mobile Air Conditioning (MAC) system with a very small impact on the environment. The system based on adsorption cooling is powered by the waste heat recovered from the engine coolant. The advantages of such a system are: a drastic reduction of the fuel overconsumption and the $\mathrm{CO} 2$ emission associated to the MAC usage, and the use of water as the refrigerant, which is a no Global Warming Potential (GWP) fluid [1] compliant with the new EU regulation and naturally available. In addition the system being based on thermal compression and not on mechanical compression, is decoupled from the engine operation and has no impact on the vehicle handling. Finally, coupled with a small fuel burner or with a solar panel it can provide air conditioning when the vehicle engine is stop. Thus the system can provide the cabin preconditioning and allows the cabin cooling for those vehicles which are also used for rest or sleeping (truck, camper). The core of the system is an adsorption chiller that has been designed, manufactured and tested at first at the ECN laboratory. It produces $2 \mathrm{~kW}$ of chilling power with a COP of 0,4. The on board overall MAC system has been designed, manufactured and installed on a Fiat Grande Punto at CRF. The testes demonstrate the potential of such device to replace conventional vapor compression system. Following this experimental work a system redesign and car integration study was done and showed the potential to further reduce the volume and weight of the adsorption cooling system to the extent that the system can be integrated fully in the engine compartment.
\end{abstract}

\section{INTRODUCTION}

The international scenario and the incoming new regulations on the vehicles $\mathrm{CO}_{2}$ emissions are increasing the need of devices and systems able to significantly reduce the overall vehicle impact on the environment. The European Commission, as part of its strategies to fulfill the Kyoto Protocol commitment on $\mathrm{CO}_{2}$ reduction, is preparing measures and regulations to limit $\mathrm{CO}_{2}$ emissions from ground transportation. According to the EU directive on the use of fluorinated refrigerants from mobile air conditioning [2], starting from 2011, due to its high GWP, the R134a will be banned and shell be replaced by low GWP fluids (less then 150). The EU Parliament has also approved a new regulation on CO2 emission for passengers car [3]. According to that regulation, by 2012 the CO2 emission target over the New European Driving Cycle (NEDC) will be reduced to $130 \mathrm{~g} / \mathrm{km}$. The regulation also include special credit, up to $7 \mathrm{~g} / \mathrm{km}$ in case of the implementation of eco-innovation. These new directives are forcing the car manufacturers and the automotive suppliers to move to new MAC systems with increased energy efficiency and based on low GWP refrigerants. The adsorption cooling technology can provide a more sustainable alternative to conventional compression cooling technology. Thermally driven adsorption cooling systems can reduce both the direct impact (avoid the use of high GWP refrigerant) and the indirect impact (reduction of the additional fuel consumption) of MAC systems on the global warming. In addition it is known that conventional internal combustion engines convert only about $30 \%$ of the fuel chemical energy into mechanical power, while the remaining $70 \%$ is lost in the ambient as heat. Technology to convert this heat into useful power are more and more under investigation and development in the automotive industry as it can be considered one of the latest opportunity to significantly improve the conventional vehicle energy efficiency. High temperature waste heat source such as the exhaust gas thermal power $\left(200^{\circ} \mathrm{C}-900^{\circ} \mathrm{C}\right)$ can be conveniently converted into mechanical/electrical power by means of systems based on thermodynamic cycle (Rankine, Stirling..) or thermoelectric generation. The low temperature level of the engine coolant $\left(80^{\circ} \mathrm{C}-90^{\circ} \mathrm{C}\right)$, make it unusable to drive such a kind of systems, but could be sufficient to operate an adsorption based heat pump.

In the past adsorption chillers have been successfully tested mainly for stationary applications such us solar air conditioning/ice making and tri-generation [4]. Automotive air conditioning was an appealing opportunity already suggested by Suzuki [5], that proposed application of adsorption cooling systems to automobiles using water as working fluid. Tchernev [6] pointed out that the automobiles engine could not provide sufficient energy from the high temperature exhaust gas to drive the adsorption machine during Page 1 of 9 
city driving or at idle conditions. On the contrary, utilization of the heat contained in the engine coolant loop may be a more appropriate solution to drive an adsorption device, as larger amount of waste heat is available at the constant temperature of about $90^{\circ} \mathrm{C}$. However for a so low temperature heat source the use of traditional water adsorbents such us zeolites $4 \mathrm{~A} / 13 \mathrm{X}$, which require higher temperature level for regeneration, was not possible. To overcome this problem, Tchernev proposed the utilization of zeolites with ZSM or Y structure as adsorbents and methanol as adsorbate. Required desorption temperature was lower than $90^{\circ} \mathrm{C}$. However, the performance were rather limited due to low latent heat of methanol [7]. Zhang [8] realized and tested in laboratory an experimental cooling unit driven by the exhaust gas of a diesel engine. The adsorber was a double-tube pipe packed with zeolite 13X grains. The obtained 0,38 Coefficient Pf Performance (COP) was interesting, but the $25.7 \mathrm{~W} / \mathrm{kg}$ Specific Cooling Power (SCP) measured was too low for practical application in vehicles. Jiangzhou [9] realized a prototype of zeolite/water adsorption chiller for a locomotive driver-cabin air conditioning. The prototype was able to deliver about $4.5 \mathrm{~kW}$ cooling power with COP of 0.25 . Again the weight of the prototype (>300 kg) was not suitable for practical application in vehicles, which imposes very strict constraints in terms of lightness, compactness and heat transfer efficiency.

The EU funded TOPMACS project was devoted to the development of compact adsorption air conditioners specifically designed for cars and trucks, aiming to came trough the major limitation encountered in the past realization. The partners of the project developed 4 cooling machines based on different working pairs: metal hydride/hydrogen, activated carbon/ammonia, silica gel/water, zeolite/water. The advanced made in the adsorption cooler technology achieved in the Project showed that the amount of waste heat freely available in the engine coolant circuit as well as its temperature level were sufficient to drive the adsorption cooling system and to produce enough cold to keep comfortable interior temperatures. Such systems were also able to improve the cooling power density up to nine times the state of the art sorption cooler, thus significantly reducing the size/weight and making already possible this technology application on board truck and with some further improvement on board passenger cars.

This paper deals with the development, manufacturing and on board testing of an air conditioning system for passenger car based on the silica gel/water adsorption cooler. Following the experimental work a system redesign and car integration study was done and indicated the potential to significantly further reduce the volume and weight of the adsorption cooling system to the extent that the system can be integrated in the engine compartment.

\section{THE THERMALLY DRIVEN AC SYSTEM CONCEPT}

Some materials have the property to absorb and release fluid molecules in a reversible way. When the fluid is absorbed by the dry sorbent material (e.g. silica-gel, zeolite, activated carbon) in what is called a reaction bed, it evaporates taking the heat from the ambient, thus generating the cooling effect. Heat is needed to "dry" the sorbent material, making it ready for a new cycle. Making use of this principle, it is possible to realize thermodynamic cycles and devices working at three temperature levels. Fig. 1 shows the basic concept of a mobile air conditioning system based on sorption cooling. The system is powered by the waste heat recovered from the engine cooling loop (high temperature). The cooling effect produces the car cabin cooling (low temperature), while the excess heat is rejected to the ambient (intermediate temperature). Conventional MAC are based on a mechanical compressor driven by the engine which has a significant impact both on the fuel economy and on the vehicle handling, particularly for small-medium size cars. Conversely a MAC based on adsorption cooling which realize a thermal compression, is mechanically decoupled by the engine and can be operated by the free energy which is normally wasted by the engine.

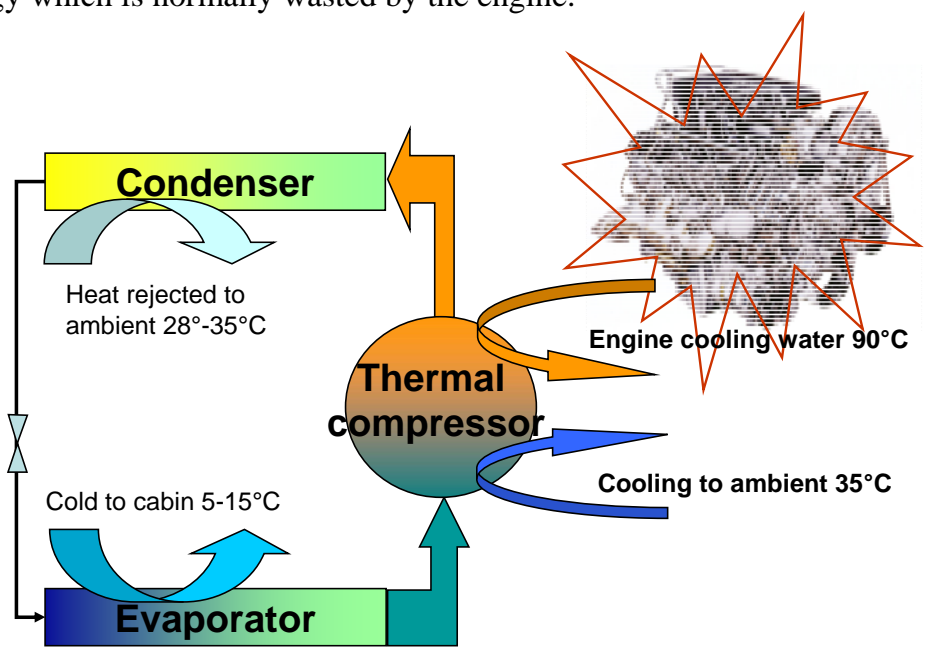

Figure 1 - Sorption cooling concept for mobile air conditioning system

Page 2 of 9 


\section{PROTOTYPE SORPTION COOLER DEVELOPMENT AND LABORATORY TESTS}

The core of the system is an adsorption chiller realized according to the drawing in Figure 2. The system is based on the working pair silicagel-water and consists of a water cooled condenser, an evaporator, two silicagel reactors, check valves to direct the refrigerant vapour flow, a condensate valve connected to a liquid level control for the evaporator and four actuated three way valves to direct the heating and cooling water circuits alternately to both silicagel reactors. Temperature and pressure sensors are installed inside the reactors, the evaporator and the condenser. Temperature sensors are also installed to measure all the inlet and outlet temperatures of the liquid circuits of the system. A PLC system controls the operation of the liquid circuit valves based on the readings of the temperature differences between the inlet and outlet of the hot water circuit.

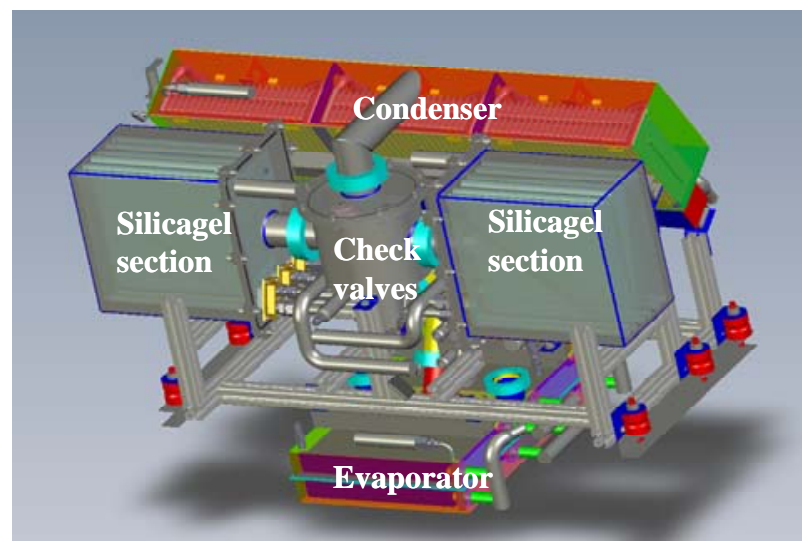

Figure 2 - Prototype adsorption chiller drawing

The thermal compressor section of the adsorption system, consists of the two reactors. Each reactor has three tube-fin heat exchangers connected in parallel. The fin side of each heat exchanger is filled with $1 \mathrm{~kg}$ of silicagel grains. The reactors are connected to a housing that contains the gravity operated refrigerant check valves. The condenser has three heat exchangers (automotive evaporators) connected in parallel and contained in a stainless steel envelope. It has internal reinforcements to withstand the forces of the internal vacuum. The evaporator has four tube-fin heat exchangers (automotive heater cores) that lie horizontally in 2 sections on top of each other. Each heat exchanger has a water layer at the lower part of the fin side. The system covered by thermal insulation material is visible in Figure 3.

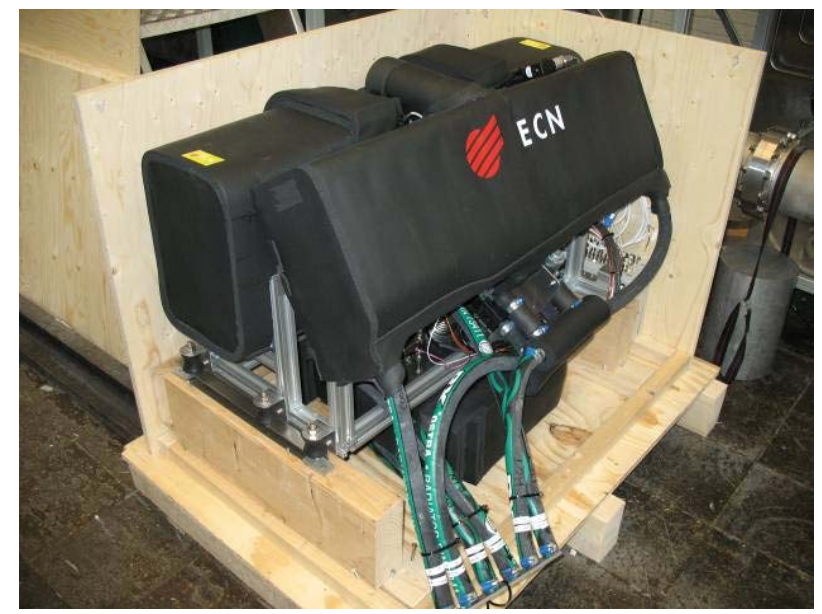

Page 3 of 9

Figure 3 - Prototype adsorption chiller 
The adsorption cooler operation requires three process fluid circuits:

- The Heating loop, which is the high temperature circuit necessary for the sorbent material regeneration

- The Cooling loop, which is the intermediate temperature circuit necessary to provide the heat rejection of the reaction beds and the condenser to the ambient

- The Chilling loop, which is the low temperature circuit which provide the cabin cooling effect

The fluid used for the process circuits is water-glycol. The target operating conditions for flow rates, temperature and thermal powers are specified in Table 1.

Table 1 - Adsorption Chiller design operating condition

\begin{tabular}{|l|c|c|c|c|c|c|}
\hline & \multicolumn{3}{|l|}{ Temperature $\left[{ }^{\circ} \mathrm{C}\right]$} & \multicolumn{2}{l|}{$\begin{array}{l}\text { Flow } \\
\text { setpoint }\end{array}$} & Power \\
\hline & $\min$ & setpoint & $\max$ & $\mathrm{m}^{3} / \mathrm{h}$ & $\mathrm{I} / \mathrm{min}$ & $\mathrm{kW}$ \\
\hline Heating & 5 & 90 & 95 & & & \\
- supply & & & & 0.72 & 12 & 4,0 \\
- return & 5 & 85 & 90 & & & \\
\hline $\begin{array}{l}\text { Cooling (condenser incl.) } \\
\text { - supply }\end{array}$ & 5 & 33 & 45 & & & \\
- return & 5 & 40 & 60 & & & \\
\hline $\begin{array}{l}\text { Chilling (evaporator) } \\
\text { - supply } \\
\text { - return }\end{array}$ & 5 & 15 & 45 & & & \\
\hline
\end{tabular}

Laboratory measurements have been done at ECN to verify the proper operation and the thermal performance of the system before installing it into the car. The prototype system was connected to a heating water circuit, a cooling water circuit and a chilled water circuit. The flow rates and temperatures of these circuits were set according to expected average values for the on-board situation, over the New European Driving Cycle. All thermal elements had an internal temperature sensor and a pressure sensor. The three external water circuits all had a flow sensor and have temperature measurements at the inlet and outlet of the adsorption system. This allows the measurement of all the thermal powers transferred by the sorption system. The laboratory test conditions were static with constant flow rates, according to the set-points defined in Table 1 . The results of these tests are reported in Figure 4 and 5 . Figure 4 shows the temperatures of the three water circuits. The thermal powers transferred by the water circuits during the operation of the system are shown in Fig.5.

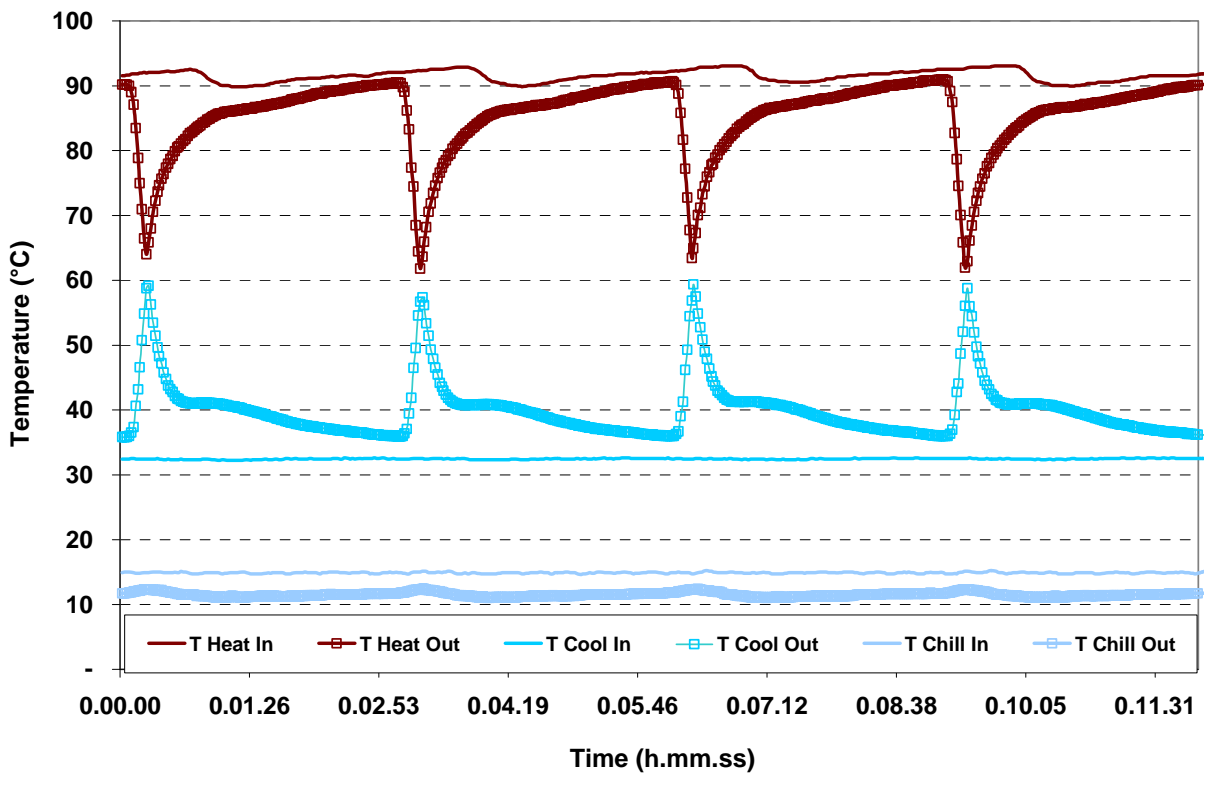

Figure 4 - Measured inlet and outlet temperatures of the heating, cooling and chilled water circuit during a laboratory test.

Page 4 of 9 


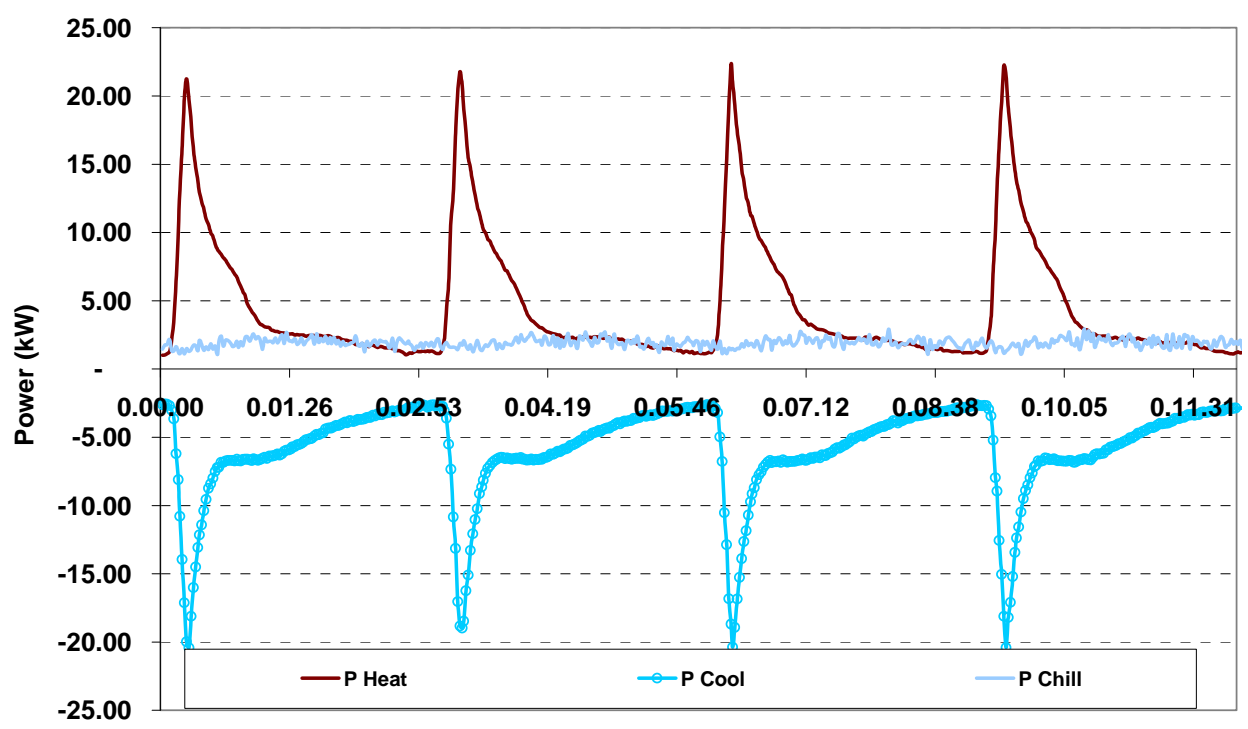

Time (h.mm.ss)

Figure 5 - Thermal powers over time of the heating, cooling and chilled water circuits during 2 operating cycles. Condensation and evaporation powers $\left(P_{\text {cond }}\right.$ and $\left.P_{\text {evap }}\right)$ are plotted on the right y-axis.

Additional performance measurements on the prototype were done by applying a range of different temperatures for the heating water, the cooling water and the chilled water inlet. The tests were conducted by varying only one of the inlet temperatures at the same time. For each condition the chilling power and COP were determined. Depending on the varying operating temperatures, the system was able to deliver $2.5 \mathrm{~kW}$ cooling power with a COP up to 0.5 .

\section{ON BOARD OVERALL SYSTEM DEVELOPMENT AND TESTING}

After the laboratory test at the ECN, the adsorption cooler was moved to the CRF with the purpose to realize a complete MAC on the car Demonstrator. A Fiat Grande Punto having a 1.41 gasoline engine was selected as the Demonstration car. This car is representative for a modern European B-segment (compact) car. The sorption cooling system was installed in the trunk space of the car because even if this development improved the cooling power density of 4 times with respect to the commercial available systems, the volume of the thermal compressor section was still too large to be integrated in the engine bay. The overall air conditioning system layout, as realized on the car Demonstrator, is shown in Figure 6. The heat rejection of the adsorption system from the condenser and the cooled silica gel reactor is done by an additional cooling water circuit that removes the heat through an additional radiator in the front of the car. The cold produced in the evaporator is transferred to a chilled water loop. The chilled water loop is pumped through the cabin aircooler which is replacing the standard evaporator, to provide the cabin cool down. Each liquid circuit has a pump, a flow measurement device and temperature sensors at the inlet and outlet of the thermal components. In addition the hot water circuit (or engine cooling water loop) has an exhaust gas heat exchanger (EGHE) which can be used to provide additional heat to the coolant loop. This reduces the time required to reach steady state operating temperatures of the engine and reduces the start-up time of the sorption cooling system. An overall electronic system control has been developed.

Figure 7 shows the car Demonstrator with the main components that have been installed.

A preliminary session of tests has been performed in the CRF garage with the car in static condition and the engine running. These tests were used for the electronic control and acquisition system debugging, as well as to tune the three fluid circuits flow rate.

Afterward a series of tests have been performed in the climatic roller bench room with the purpose to optimize the system and to assess the system performance. Tests have been performed in different conditions including different ambient temperatures, different driving cycles (constant speed, NEDC) and simulating the engine start\&stop operation which is becoming a standard on several European cars. Figure 8 shows the chilling power and the engine rotational speed over the NEDC. As it can be clearly notice, the system is able to provide a constant cooling power while the driving cycle is strongly varying. This is due to the thermal inertia of the engine cooling water circuit and the adsorption chiller itself behaviour and can represent an advantage compared to the conventional

Page 5 of 9 
MAC system in which the mechanical compressor speed is related to the engine speed and produces a fluctuating cooling power over a fluctuating driving cycle. For the same reason, when the thermal engine was cut-off to simulate the start\&stop operation, the system was able to provide the same cooling power for the time of the cycle, which means about 6 minutes. In the case of the NEDC the average cooling power was about $900 \mathrm{~W}$, which is sufficient amount to keep the car cabin at comfortable temperature, but which is too low to provide the cool down performance (get the internal temperature of the car cabin down to comfortable levels after it is parked in the sun in severe summer conditions). Nevertheless it has to be considered that coupling the system with a small fuel burner, the type already installed on some car as auxiliary heating system, it is possible to operate the system when the main engine is shut off. This means that a cabin preconditioning is possible, reducing the temperature inside the car before the engine is started up. In this case the maximum required cooling power could be significantly lower and compatible with the potentialities of an adsorption cooling system.

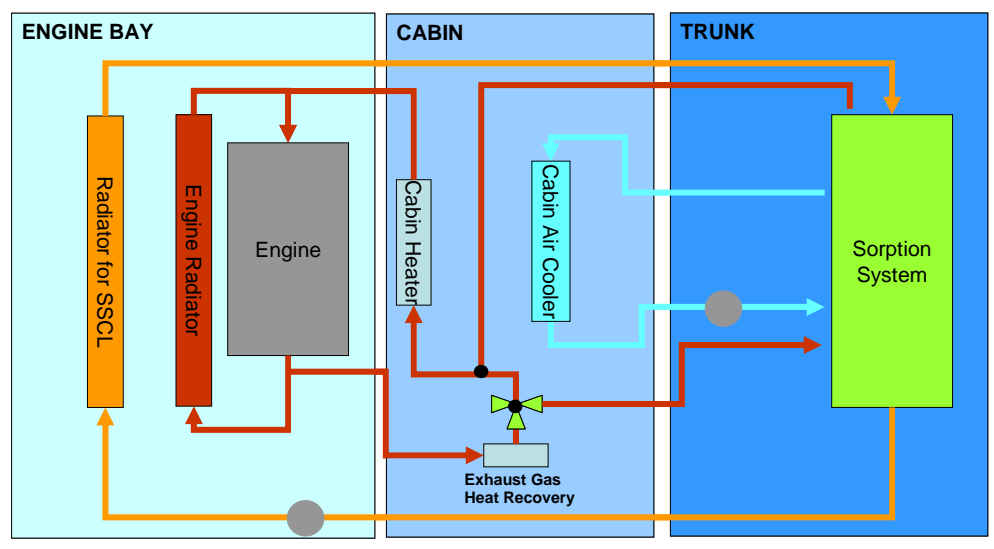

Figure 6 - Overall Air Conditioning System layout

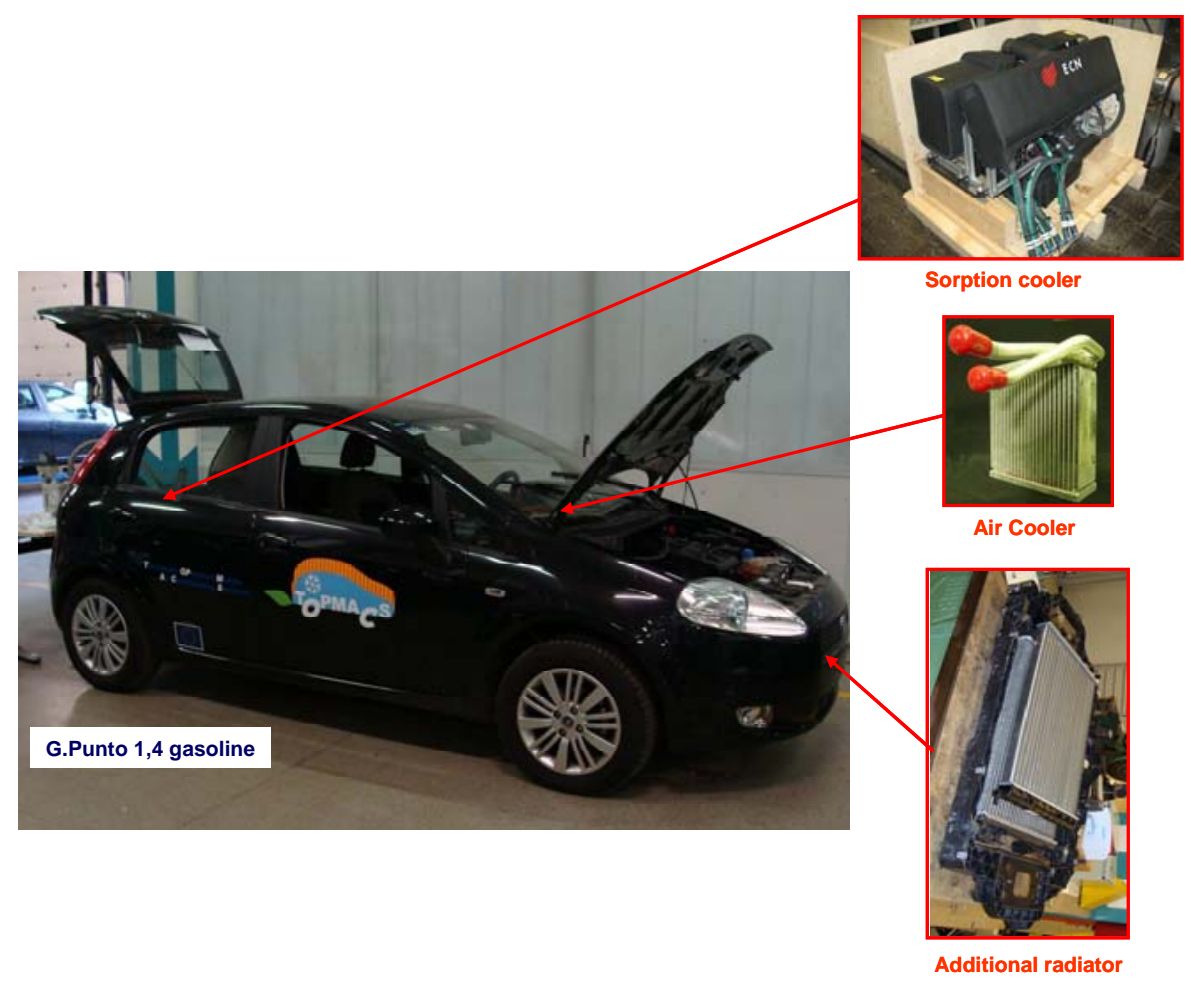

Figure 7 - The Car Demonstrator main components 


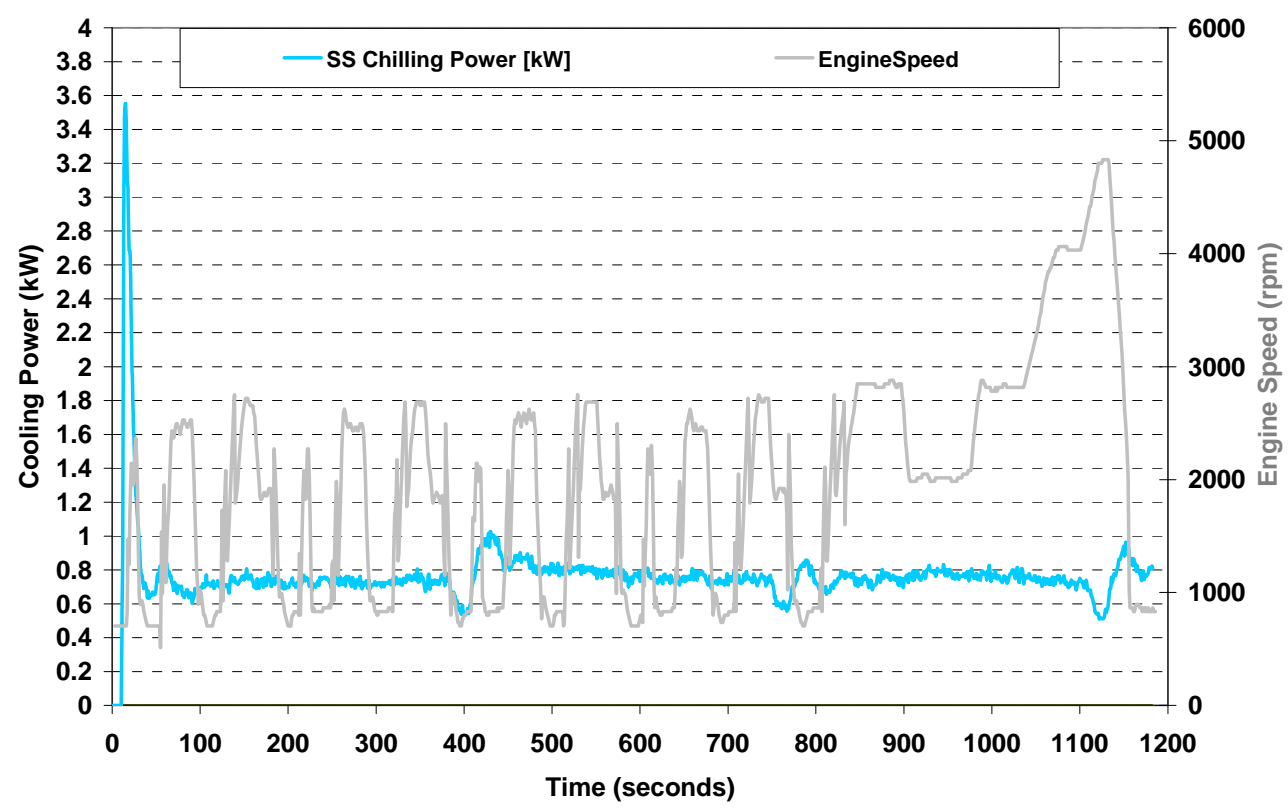

Figure 8 - Test Results over the NEDC

\section{REDESIGN AND SYSTEM INTEGRATION STUDY}

The current size of the silica gel reactors, which constitute the 'thermal compressor' of the adsorption chiller prototype was too big to have it installed in the engine compartment of the car. However, installing it in the trunk of the car made it necessary to apply indirect water cooled condenser and evaporator, which adds to the complexity of the system with secondary loops, as well as to the overall weight and volume. With Valeo support, a second version was designed of a compact sorption cooling system capable to be implemented on the FIAT Punto underhood. The sorption cooling reactors with vapor distribution system and liquid distribution system were redesigned with the aim to fit in a packaging of 400 x 400 x 200 mm. The design drawings are shown in Figure 9.

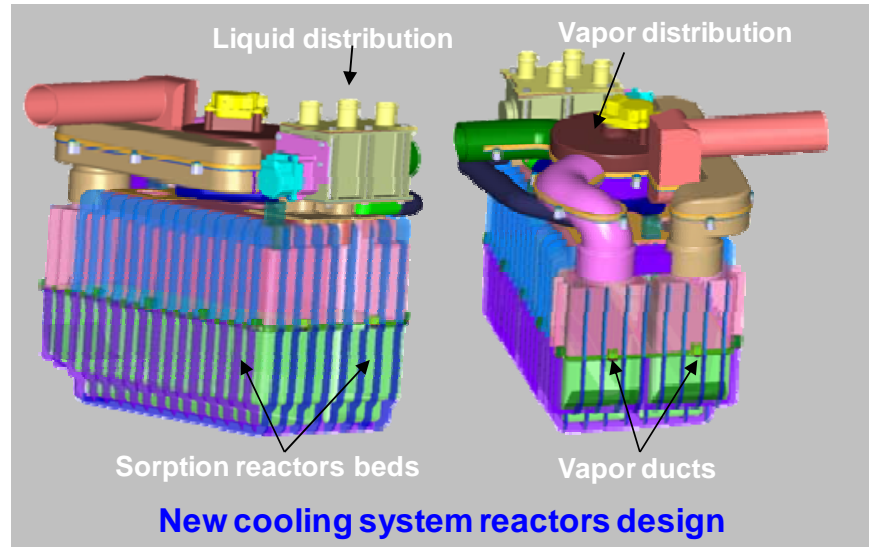

Figure9 - Design drawing for the silicagel reactors combined with liquid and vaport distribution valves.

The system was optimized and integrated into the numerical mockup of the Fiat Punto underhood (Figure 10). The system is implemented close to the engine and the dashboard. That allows using direct air cooled condenser and evaporator and avoid having secondary loops. The study shows no major interferences with vehicle structure and with the engine. Minor components of the engine (tubes, ducts, expansion vessel...) need to be repositioned. In particular, the battery needs to be moved 20 to $30 \mathrm{~mm}$. 


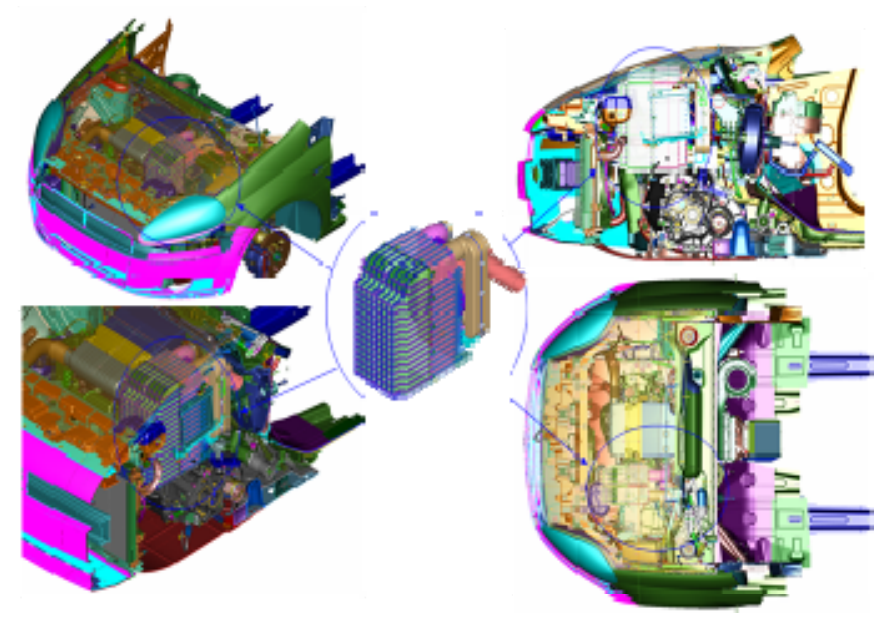

Figure 10- Overview of sorption chiller system integrated in the engine compartment of the Fiat Punto.

\section{SUMMARY}

A prototype adsorption cooling system for use as a mobile air conditioning system was designed and constructed. The performance of the system was measured both in the laboratory and on board the vehicle under varying operating temperatures and cycle times. Depending on the operating temperatures, the system can deliver up to $2.5 \mathrm{~kW}$ cold at a COP in the range of 0.3 to 0.5 .

- The present cooling power is unable to provide the cabin cool-down, but it is suitable to maintain the steady state conditions.

- $\quad$ Powering heat with a small fuel burner could provide preconditioning and allow the cooling system downsizing.

- The chosen switching control works properly in fluctuating flow and temperature conditions.

- With the engine switch off, the system is able to maintain the cooling power for the time of the cycle (good option for stop\&start powertrain).

- During dynamic driving conditions the system provides constant cooling power.

- $\quad$ Performance could be increased by improving the heat rejection system (lowering cooling temperature) and improving the cabin heat exchanger efficiency.

- Integration of the sorption system in the car is an important issue to improve performance, volume weight.

\section{CONCLUSIONS}

The results of this work demonstrate that the concept of a waste heat driven adsorption cooling system can be applied for comfort cooling purposes on vehicles. The amount of waste heat that is freely available in the engine coolant circuit as well as its temperature level is sufficient to drive the adsorption cooling system and to produce enough cold to keep comfortable interior temperatures. The technology can in this way contribute to a reduction of the fuel consumption and the overall CO2 emissions of a vehicle, as well as to eliminate to use of GWP refrigerants, meeting the new EU regulation on MAC systems.

The development of adsorption cooling technology for MAC application requires further research and development effort. These efforts should include

- $\quad$ Further reduction of system volume and weight

- $\quad$ application of direct condensation and direct evaporation

Page 8 of 9 


\section{REFERENCES}

1. GWP is an index which measure of how much a given mass of greenhouse gas is estimated to contribute to global warming as defined by the IPCC Third Assessment Report Climate Change 2001.

2. European Union, directive 2006/40/EC relating to emissions from air-conditioning systems in motor vehicles, Official Journal of the European Union, 161, 12-18, 2006

3. Regulation (EC) no 443/2009 of the European Parliament and of the council, "Setting emission performance standards for new passenger cars as part of the community's integrated approach to reduce co2 emissions from light-duty vehicles".

4. Critoph R E, Zhong Y, Review of trends in solid sorption refrigeration and heat pumping technology, Proc. IMechE, Vol. 219 Part E: J. Process Mechanical Engineering, (2005).

5. Suzuki M, Application of adsorption cooling system to automobiles, Heat Recovery Syst. CHP, 13 (1993) 335-340.

6. Tchernev D, A waste heat driven automotive air conditioning system, Proc. Of the Int. Sorption Heat pump Conference, Munich, Germany, March 24-26 (1999).

7. Restuccia G, Freni A, Russo A, Vasta S, Experimental investigation of a solid adsorption chiller based on a heat exchanger coated with hydrophobic zeolite, Applied Thermal Engineering, 25 (2005) 1419-1428.

8. Zhang L Z, Design and test of an automobile waste heat adsorption cooling system, Applied thermal engineering, 20 (2000) 103114.

9. Jiangzhou S, Wang R Z, Lu Y Z, Xu Y X, Wu J Y, Experimental investigations on adsorption air-conditioner used in internalcombustion locomotive driver-cabin, Applied thermal engineering, 22 (2002) 1153-1162.

\section{CONTACT INFORMATIONS}

Daniela Magnetto

Interiors and Thermal Systems KH Engeneer

Centro Ricerche Fiat

Strada Torino 50, Orbassano 1004,3 ITALY

Email daniela.magnetto@crf.it

Robert de Boer

ECN, Efficiency \& Infrastructure

PO Box 1, 1755 ZG Petten, The Netherlands

Email r.deboer@ecn.nl

Abdelmajid TAKLANTI

Valeo Systemes Termique

8 rue Louis Lormand

BP513 - La Verriere

78321 Le Mesnil Saint Denis Cedex, FRANCE

Emailabdelmajid.taklanti@valeo.com

\section{ACKNOWLEDGMENTS}

The TOPMACS project was partially funded by EU-FP6 Sustainable Surface Transport Program, contract TST4-CT-2005-012471

\section{DEFINITIONS/ABBREVIATIONS}

MAC

GWP

NEDC

COP

Page 9 of 9
Mobile Air Conditioning

Global Warming Potential

New European Driving

Cycle

Coefficient of

Performance 